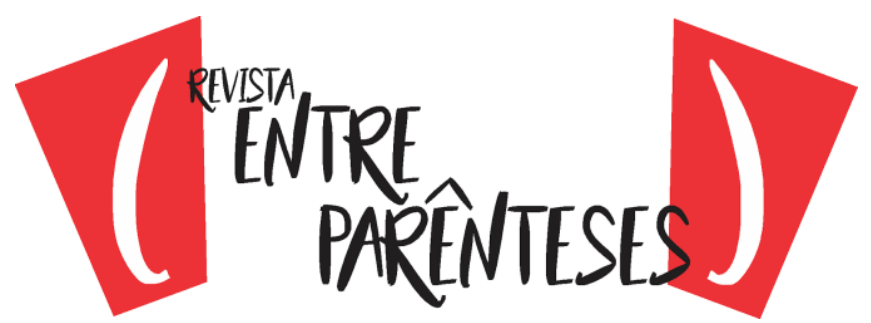

\title{
"LONGE DOS DETRITOS PRIVADOS DA VIDA": O DESENRAIZAMENTO DE KAUSHIK EM TRÊS CONTOS DE TERRA DESCANSADA, DE JHUMPA LAHIRI
}

\author{
https://doi.org/10.32988/rep.v2n9.1121
}

\author{
José Vilian Mangueira ${ }^{1}$ \\ Universidade Estadual de Paraíba \\ (vilian_mangueira@yahoo.com)
}

\begin{abstract}
Resumo: Levando em conta o destaque que a crítica especializada dá à obra de Jhumpa Lahiri, como a representação da diáspora do indiano em solo ocidental, procuramos interpretar as três narrativas da segunda parte de Terra descansada, "Parte II - Hema e Kaushik", dando ênfase ao modo como Kaushik Choudhuri, o protagonista masculino, lida com os espaços geográficos nos quais está inserido. Suas sucessivas mudanças de locais de moradia, aliadas à perda da mãe, que é símbolo do espaço de nascimento, fazem com que o protagonista fuja de tudo aquilo que possa lhe oferecer uma possibilidade de se enraizar (DELEUZE \& GUATTARI, 1995). Isso se evidencia no afastamento do país onde nasceu; na fuga da casa onde a família morou nos Estados Unidos; na escolha profissional que ele faz e na falta de desejo de construir algo oficializado com a mulher que ama. Desse modo, os espaços identificados como pátria (Estados Unidos), terra adotiva (Índia), espaços de trabalho (diferentes países) e espaço de sepultamento (Tailândia) oferecem um entendimento para a leitura que empreendemos aqui. Como não consegue fincar raízes e florescer (metáforas utilizadas para marcar o ajustamento em solo dos personagens das narrativas desse livro), Kaushik termina sua história sendo engolido pelo espaço das águas, elemento que representa morte e renascimento (CHEVALIER \& GHEERBRANT, 2009; BACHELARD, 1997).
\end{abstract}

Palavras-chave: Espaço; Diáspora indiana; Jhumpa Lahiri.

\section{"AWAY FROM THE PRIVATE DETRITUS OF LIFE": KAUSHIK'S UNROOTEDNESS IN THREE SHORT-STORIES FROM UNACCUSTOMED EARTH, BY JHUMPA LAHIRI}

\begin{abstract}
Considering the value that critics pay to the work of Jhumpa Lahiri as a representation of the Indian diaspora on the Western soil, we will investigate the three narratives from the second part of Unaccustomed Earth, "Part II - Hema and Kaushik," examining how the male protagonist Kaushik Choudhuri deals with the geographic spaces in which he is placed. His continuous changes of residence, associated with the loss of his mother, who is a symbol of birth, make him run way from everything that can offer him the possibility of putting down roots (DELEUZE \& GUATTARI, 1995). This is emphasized by his displacement from his motherland; by his fleeing his family home in the USA; by his professional life and also by his lack of desire to build a legitimate relationship with the woman he loves. Therefore, the spaces identified as homeland (the United States), adopted land (India), work space (several countries), and burial space (Thailand) offer an understanding of our interpretation of this reading. Since he is unable to grow roots and flourish, metaphors used to mark the adjustment of the main character to a soil, Kaushik ends his narrative being swallowed up by a liquid space, element that represents death and rebirth (CHEVALIER \& GHEERBRANT, 2009; BACHELARD, 1997).
\end{abstract}

Keywords: Space; Indian diaspora; Jhumpa Lahiri.

\footnotetext{
${ }^{1}$ Doutor em Letras pela Universidade Federal da Paraíba. Professor de Literatura Anglo-Americana do curso de Letras do Campus III da Universidade Estadual da Paraíba - UEPB.
} 


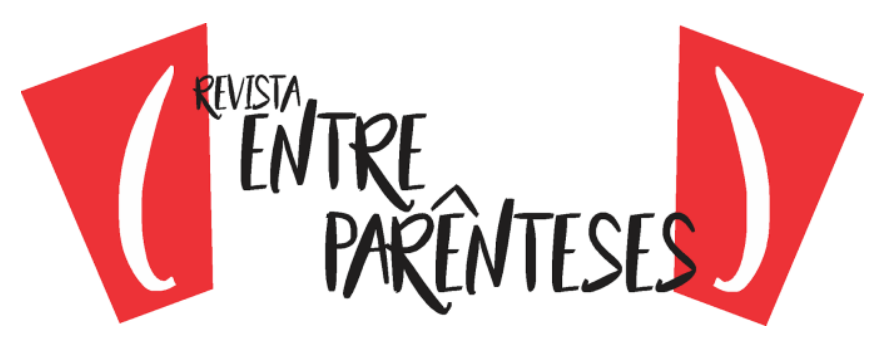

\title{
“LEJOS DE LOS DETRITOS DE LA VIDA PRIVADA": EL DESARRAIGO DE KAUSHIK EN TRES CUENTOS DE TIERRA DESCANSADA, POR JHUMPA LAHIRI
}

\begin{abstract}
Resumen: Teniendo en cuenta el énfasis que la crítica especializada le da al trabajo de Jhumpa Lahiri, como la representación de la diáspora india en el suelo occidental, buscamos interpretar las tres narrativas de la segunda parte de Tierra Descansada, "Parte II - Hema y Kaushik", dando énfasis al modo como Kaushik Choudhuri, el protagonista masculino, trata los espacios geográficos en los que se inserta. Sus sucesivos cambios de lugares de residencia, aliados a la pérdida de su madre, que es un símbolo del espacio de nacimiento, hacen que el protagonista huya de todo lo que le ofrezca la oportunidad de echar raíces (DELEUZE \& GUATTARI, 1995). Esto se pone evidente en el distanciamiento del país em donde nació; en el escape de la casa em que vivía la familia en los Estados Unidos; en la elección profesional que hace; y en la ausencia de un deseo de construir algo oficial con la mujer que ama. Se reconoce que, los espacios identificados como patria (Estados Unidos), tierra adoptada (India), espacios de trabajo (diferentes países) y espacio de entierro (Tailandia) ofrecen una comprensión de la lectura que emprendemos aquí. Como no logra echar raíces y florecer (metáforas utilizadas para marcar el ajuste en suelo de los personajes en las narraciones de este libro), Kaushik termina su historia al ser tragado por el espacio de las aguas, elemento que representa la muerte y el renacimiento (CHEVALIER \& GHEERBRANT, 2009; BACHELARD, 1997).
\end{abstract}

Palabras clave: Espacio; Diáspora india; Jhumpa Lahiri.

Nascida em Londres e radicada nos Estados Unidos, a escritora Jhumpa Lahiri retrata em suas histórias as vivências dos imigrantes indianos/bengaleses em território Ocidental. A crítica literária sobre a obra da autora tem mostrado que seus textos se apresentam como intérpretes proeminentes da condição pós-colonial da diáspora indiana. Desse modo, sua literatura destaca as angústias de uma população inserida em uma condição dual de cidadão transcontinental.

Autora renomada nos Estados Unidos e, também, em outros países, Jhumpa Lahiri estreou no cenário literário com o livro de contos ganhador do Pulitzer de ficção Interpreter of maladies (Intérprete de males), em 1999. Desde então, ela já se destacou com outras obras de relevância, tanto no gênero conto como no romance: The namesake ( $O$ xará), de 2003; Unaccustomed Earth (Terra descansada), de 2008, e Lowland (Aguapés), de 2013. Em seu livro de contos Terra descansada, a escritora observa a segunda geração de indianos/bengaleses nascidos/crescidos nos Estados Unidos, imersos em um ambiente Ocidental fora da casa dos pais. Inseridos em tal contexto, eles vivenciam um senso de isolamento e, em certos casos, alienação diante do que os cerca. Essa segunda geração ainda encontra-se diante de um processo de aculturação, em que os valores culturais do 


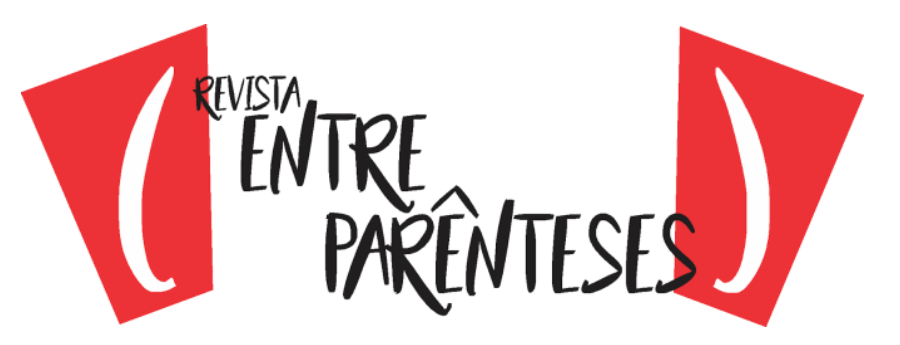

novo espaço estão internalizados, mas um senso de nostalgia pela Índia dos seus pais ainda é perceptível.

Terra descansada possui oito contos e é dividido em duas partes. $\mathrm{Na}$ primeira, são apresentados diferentes personagens lidando com os conflitos de duas gerações familiares morando em território americano. Cinco histórias compõem esta primeira parte: "Terra descansada", "Inferno-céu", "Opções de acomodação", "Só bondade" e "Da conta de ninguém". Na segunda parte do livro, três histórias seguem a vida de duas personagens - Hema e Kaushik. Em relação à obra como um todo, é possível afirmar que os contos possuem uma interligação, uma vez que as histórias falam sobre temas que marcam a vida dos diferentes personagens: relações familiares, aculturação, pertencimento e terra natal versus terra estrangeira.

Diante dessas temáticas presentes na obra, a nossa proposta de análise para este trabalho consiste em interpretar o modo como Kaushik Choudhuri, o protagonista masculino, lida com os espaços geográficos nos quais está inserido. Suas sucessivas mudanças de locais de moradia, aliadas à perda da mãe, que é símbolo do espaço de nascimento, fazem com que o protagonista fuja de tudo aquilo que possa the oferecer uma possibilidade de se enraizar, crescendo como um rizoma, "no coração de uma árvore, no oco de uma raiz ou na axila de um galho" (DELEUZE \& GUATTARI, 1995, p. 23). Assim, buscamos analisar o protagonista masculino Kaushik Choudhuri, numa tentativa de entender o modo como a narrativa retrata um indivíduo em constante atitude de nomadismo, vivenciando a desterritorialização e experimentando uma identidade fluida. Suas andanças mostram que ele "[...] desarticula as identidades estáveis do passado" abrindo "a possibilidade de novas articulações" (HALL, 2006, p. 17-18).

Com relação ao enredo das três narrativas que compõem a parte do livro intitulada "Hema e Kaushik", temos no primeiro conto - "Uma vez na vida" - a história da ligação das duas famílias dos protagonistas. Contada pela voz de Hema, a narrativa mostra a volta de Kaushik e sua família para os Estados Unidos, no ano de 1981, quando eles passam um tempo como hóspedes na casa de Hema. Aos 13 anos, a protagonista e narradora sente-se atraída pelo jovem Kaushik, que se mantém sempre isolado e distante, até confessar para ela, durante uma caminhada 


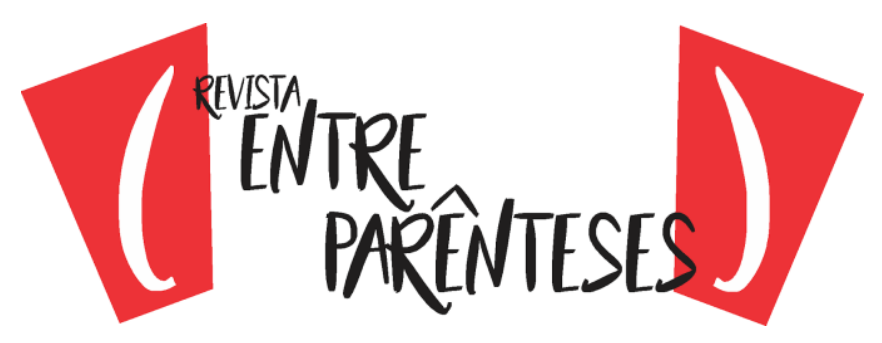

a um cemitério particular, que a mãe dele estava com câncer. Em "Fim de ano", a voz que comanda a narrativa é a de Kaushik. Nessa parte do livro, é contada a ida do jovem estudante universitário até a casa do pai, para passar as férias de fim de ano e conhecer a nova esposa do seu genitor. Como ele não consegue se ajustar à vida do pai, na companhia da madrasta e das duas novas irmãs, Kaushik tem um acesso de raiva ao ver as meninas, Rupa e Piu, mexendo em velhas fotografias de sua mãe. Assim, ele deixa a casa do pai para vagar pelo litoral americano, até o momento em que enterra as fotografias de sua mãe. No último conto dessa trilogia, "Em terra", a voz narrativa é de uma terceira pessoa que conta o encontro de Hema e Kaushik em Roma. Os dois iniciam um relacionamento amoroso intenso e, quando se separam, ele quer começar uma nova vida em Hong Kong, e ela viaja à Índia para casar. Assim, a relação dos dois é desfeita totalmente. De férias em uma praia da Tailândia, Kaushik é tragado pelo mar, depois que o tsunami de 2004 passa pela Ásia. Sabemos de sua morte quando a narrativa devolve a voz a Hema.

No primeiro conto, como a perspectiva é a da protagonista feminina, temos poucas informações sobre o protagonista masculino. Mesmo assim, são-nos oferecidos alguns pontos importantes sobre o comportamento e a história do jovem Kaushik. Inicialmente, temos a mudança espacial da família Choudhuri, em 1974, quando o pai do protagonista consegue uma boa oportunidade de emprego em seu país de origem. Essa constitui a primeira mudança espacial de Kaushik. Mas ela tem um peso menor, pois ele ainda é muito pequeno para perceber a diferença entre os dois locais de moradia; além disso, ele foi criado ao modo americano estando em solo indiano. Mesmo assim, a troca de localidade causa desconforto para Kaushik: "Ele ficou furioso quando fomos embora, e agora está furioso porque estamos aqui de novo" (LAHIRI, 2009, p. 272). Mas sua volta para os Estados Unidos é algo realmente doloroso para ele. Inicialmente porque, diferente do que ocorre com sua ida para o Oriente, a volta ao Ocidente tem um motivo negativo: a mãe vem morrer longe dos familiares, para evitar ser vista com piedade. Ele ainda tem que conviver com um espaço de moradia de outra família, por isso ele vive tão solitário, sem encontrar um lugar seu na casa. Quando Hema Ihe pergunta se ele detesta estar naquele espaço, Kaushik responde: "Eu gostava de morar na Índia" (LAHIRI, 2009, 


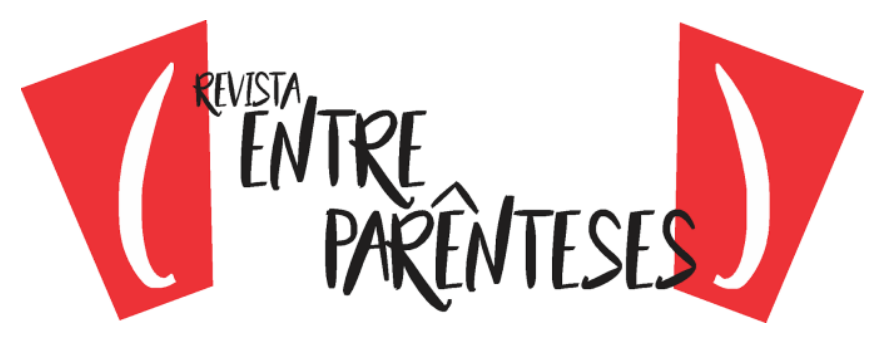

p. 276). Estrangeiro no espaço menor, a casa, e no maior, o bairro, ele acaba passando boa parte de seu dia em caminhadas solitárias:

Você passava a menor quantidade de tempo possível em casa, e saía para caminhar no frio pela mata e por ruas onde era o único pedestre. Certa vez, quando estava no ônibus escolar voltando para casa, vi você e fiquei chocada ao constatar como tinha ido longe (LAHIRI, 2009, p. 278).

Como bem enfatiza a narradora protagonista desse primeiro conto, 0 espaço da casa é algo pouco agradável para Kaushik. Isso fica evidente quando, fora da casa, em uma caminhada debaixo da neve, ele socializa de forma amigável com Hema. É nesse momento que a narradora observa que ele agia "parecendo feliz pela primeira vez desde que havia chegado" (LAHIRI, 2009, p. 284). Esta observação de Hema vai se confirmar quando eles brincam de jogar bolas de neve um no outro e quando ele se abre com ela, contando o grande segredo que sua família esconde: a doença terminal da mãe. O espaço onde essa conversa ocorre é simbólico para se entender outras cenas que virão nas duas histórias restantes dessa parte do livro: um cemitério particular da família Simonds, contendo seis lápides. Assim, em um lugar que indica morte, Kaushik conta sobre a razão de a família voltar para os Estados Unidos, dividindo com Hema a grande certeza de que em breve sua mãe estaria morta: "Ela vai se operar na primavera, mas é só para ganhar mais um pouco de tempo. Ela não quer que ninguém aqui saiba. Só no fim" (LAHIRI, 2009, p. 286). É depois de revelado o estado terminal da mãe que o leitor compreende o título do conto, "Uma vez na vida", referente à viagem em primeira classe que o Dr. Choudhuri deu à esposa como presente, uma vez que esta seria a última viagem da família: “Foi meu presente de quarenta anos', explicou [ParulMashi]. Ela olhou para o seu pai com um sorriso. 'Uma vez na vida, certo?'” (LAHIRI, 2009, p. 266).

Outro fato importante revelado nessa conversa no cemitério é a fala de Kaushik que expressa seu desejo de oferecer à mãe um funeral cristão, com enterro, e não o funeral hindu, com cremação. A descoberta das seis lápides de membros da mesma família parece oferecer ao personagem masculino uma chance de manter a mãe presente mesmo depois de morta. Por isso, ele afirma: "Isso (as lápides juntas 


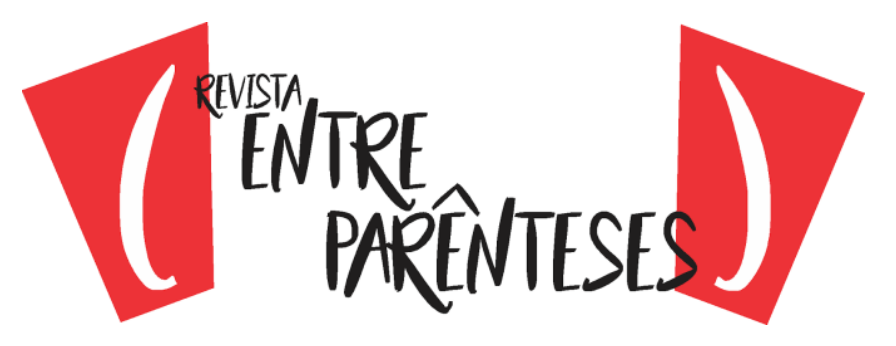

da família) me faz desejar que não fôssemos hindus, para minha mãe poder ser enterrada em algum lugar. Mas ela nos fez prometer jogar suas cinzas no Atlântico" (LAHIRI, 2009, p. 285). Dois pontos devem ser destacados aqui, neste trecho. Primeiramente, o desejo de Kaushik de enterrar a mãe em um lugar. Como ele não consegue, fará um ritual de enterro, no segundo conto, das coisas da mãe. Isso vai acontecer porque ele quer sepultar a memória da sua mãe da invasão das filhas da nova esposa de seu pai. Esse ritual de sepultamento ainda simboliza seu desejo de vencer o luto pelo qual tem passado, desde que a mãe morreu. Isso vai fazer com que ele se afaste totalmente da casa do pai, indo para sempre viver como nômade. O segundo ponto dessa fala diz respeito ao desejo de a mãe ter suas cinzas jogadas ao mar, elemento com o qual ela sempre se ligou. É nesse espaço líquido, com uma gama de significados, que o protagonista irá terminar seus dias, quando um tsunami atinge o lugar onde ele está passando férias.

De tudo o que foi apontado sobre este primeiro conto, destacamos, inicialmente, a forma dolorosa como o protagonista masculino Kauski Choudhuri vivencia o movimento de mudança dos Estados Unidos para Índia, em 1974, e, depois, de volta da Índia para os Estados Unidos, no ano de 1981. Morando em solo Indiano como um americano e vivendo, inicialmente, num lar que não é seu na América, ele parece estar sempre fora do seu lugar.

O segundo conto, "Fim de ano", é narrado pelo próprio Kaushi e conta sobre sua volta à casa da família, depois que o pai contrai novo matrimônio. A troca de narrador e a não identificação precisa da pessoa com quem esse narrador fala (Você) apontam para um ponto importante nessas histórias: há uma imprecisão entre as pessoas que conversam nos três contos, demarcando uma indeterminação para o leitor, que reforça a falta de vínculos precisos da vida de Kaushik, mote das três histórias. Quanto ao tempo decorrido, há uma passagem de cinco anos entre essa narrativa e o que é contado em "Uma vez na vida". Os pontos principais deste conto são o novo casamento do pai do protagonista e as dores que o jovem tem que enfrentar diante do luto ainda vivenciado por ele pela perda da mãe.

Morando no campus da universidade de Swarthmore, onde estuda, longe da casa do pai, Kaushik só vai saber que o pai viajou para a Índia e lá se casou 


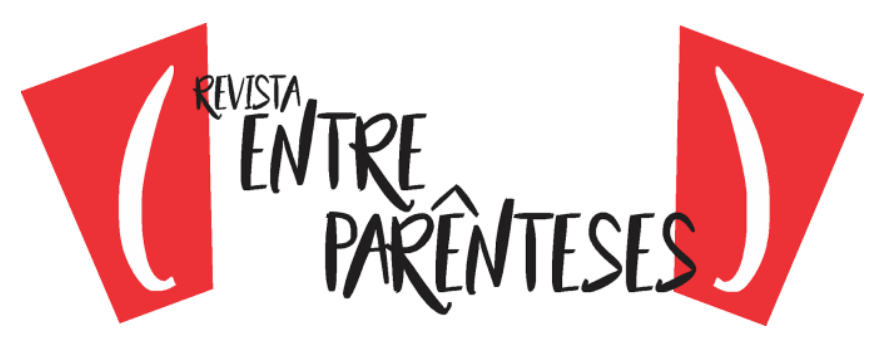

quando este liga para o filho: "Eu não compareci ao casamento do meu pai. Nem sequer sabia que tinha havido um casamento até meu pai me ligar em um domingo" (LAHIRI, 2009, p. 289). Pelo que nos é informado nessa abertura do conto, vemos que há pouca ligação entre pai e filho, desde que a senhora Parul Mashi morreu. Um fato que merece atenção nessa parte inicial do conto é a relação entre o protagonista e sua namorada, Jessica. Embora vivenciando uma relação recente, ele não consegue se abrir muito com a jovem, pois ela não sabe nada sobre a vida de Kaushik: "Ela não sabia nada sobre a minha família, sobre a visita recente do meu pai a Calcutá, nem sobre a morte da minha mãe no verão anterior à minha entrada na faculdade" (LAHIRI, 2009, p. 293). É o choque da notícia do casamento do pai que faz com que o rapaz se abra um pouco com Jessica. Isso reforça mais a dificuldade do protagonista de criar laços íntimos.

Com essa informação sobre a vida nova do pai, Kaushik volta para o seu antigo lar, a casa onde a família viveu os últimos dias de Parul. Além de encontrar a casa habitada por três novas moradoras - Chitra e suas duas filhas, Rupa e Pio Kaushik Choudhuri perde o espaço individual que habitava no lar da família. O seu antigo quarto fica para as meninas, e ele tem que se mudar para o quarto de hóspedes, uma área mais afastada, que "ficava no primeiro pavimento da casa, em uma ala separada, depois de um corredor atrás da cozinha" (LAHIRI, 2009, p. 305). Como aconteceu no conto anterior, mais uma vez, o jovem fica sem um espaço que Ihe pertença.

Nessa narrativa, a figura da mãe morta e as lembranças do tempo que viveu com ela na casa da família são os pontos mais relevantes para o protagonista. Simbolicamente, a mãe dele vai se constituir numa metáfora para o espaço identificado como lar, seja o micro espaço, a casa, seja, ainda, o macro, o país. No micro espaço, a mãe morta estará presente na lembrança do protagonista, que constantemente faz comparação entre Parul Mashi e Chitra. À medida que vai passando o tempo no seu antigo lar, o protagonista percebe que os sinais que identificam aquele lar como o espaço em que a mãe viveu vão desaparecendo. Assim, ele não consegue sentir-se bem na casa do pai. Isso fica evidente através do primeiro sentido que Ihe é aguçado ao adentrar o espaço: "Ao entrar na casa, 


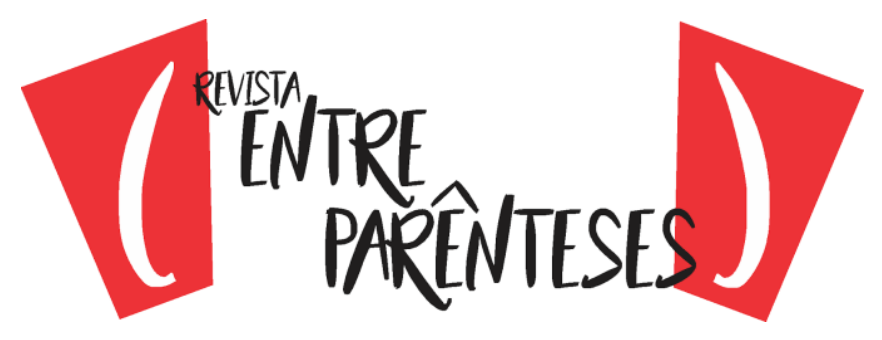

estranhei o forte cheiro de comida que pairava no ar" (LAHIRI, 2009, p. 296). O cheiro de comida em nada lembra o tempo em que a mãe mal entrava na cozinha. Nas cenas que se seguem a esta percepção, a expressão "minha mãe" vai se repetir constantemente, como forma de Kaushik espantar o cheiro da nova moradora da casa, sempre destacando o antes e o depois da presença da mãe.

O conto ainda mostra que Parul Mashi é responsável por transformar em lar o espaço onde ela estava: ela sempre carregava objetos de um lugar para outro, ao se mudar, fazendo com que as memórias dos antigos espaços fossem sempre preenchidas no novo. Mas a sua morte faz com que os outros dois membros da família se percam na casa em que escolheram morar na segunda mudança da família para os Estados Unidos. Assim, o filho vai estudar longe do pai e o pai arruma uma nova esposa indiana.

Inserido novamente no espaço da casa em que o pai mora, Kaushik vai entender que aquele lugar não Ihe pertence mais. Isso fica evidente quando ele tem que dormir no quarto de hóspedes, pois as suas irmãs postiças, Rupa e Piu, se instalam em seu antigo quarto. Assim, ele se aloja no cômodo mais afastado da casa de sua família: "O quarto de hóspedes ficava no primeiro pavimento da casa, em uma sala separada" (LAHIRI, 2009, p.305), destacando seu isolamento diante da nova constituição familiar do pai. Sobre esse ponto, Srijoni Rahman afirma que "Já se sentindo desconectado da casa onde a sua mãe morta foi substituída por outra mulher, Kaushik está vividamente ciente da perda do 'lar' e da identidade"2 (RAHMAN, 2017, p. 04, tradução nossa).

Para se livrar definitivamente do espaço da casa em que morou antes da morte da mãe e, também, numa tentativa de fazer uma ação ritualística para vencer o luto pela perda da mãe, o personagem principal deixa abruptamente a morada do pai, depois de encontrar as duas irmãs postiças mexendo nas coisas que pertenciam a Parul Mashi. $O$ trajeto que ele escolhe para fugir é significativo, pois ele é guiado pela presença do mar, um elemento importante para o destino final do rapaz:

\footnotetext{
2 "Already feeling disconnected from the house where his dead mother has been replaced by another woman, Kaushik is vividly aware of a loss of 'home' and identity".
} 


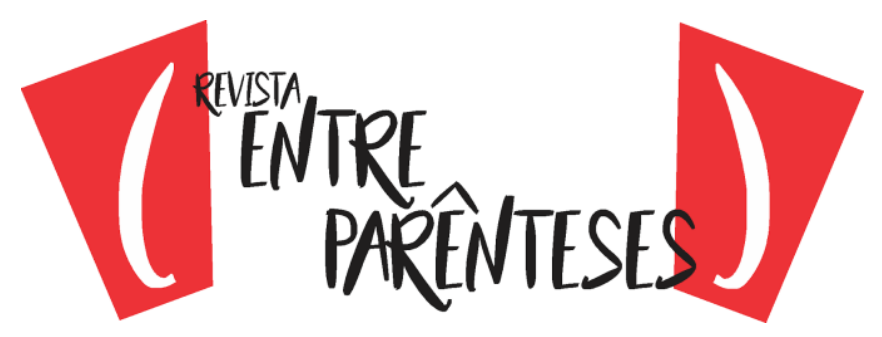

De vez em quando eu via o mar: pequenas ilhas, faróis listrados, finos pontais de terra. O frio era brutal demais para sair do carro, mas de vez em quando eu saía, para olhar o oceano ou explorar um pedaço de trilha [...] a água era o elemento mais inclemente de todos, às vezes quase negra, fria o suficiente para matar, eu sabia, violenta o suficiente para me partir em pedaços (LAHIRI, 2009, p. 331).

Longe do seu último lar e já na borda da fronteira entre seu país natal Os Estados Unidos - e o Canadá, Kaushik experimenta pela primeira vez a sensação de não ter ligação alguma com ninguém: "Não ansiava pela companhia de ninguém" (LAHIRI, 2009, p. 332). Ele também descobre que viajar solitariamente é o que the conforta: "Nunca tinha viajado sozinho antes, e descobri que gostava disso. Ninguém no mundo sabia onde eu estava, ninguém era capaz de me conectar. Era como estar morto" (LAHIRI, 2009, p. 332). A única ligação que ele mantém, mesmo que involuntariamente, é com a mãe morta: "aquela minha fuga me permitia experimentar o tremendo poder que minha mãe possuía para sempre" (LAHIRI, 2009, p. 332). Todo esse trecho final, que alude ao poder da mãe, será retomado na cena da morte do jovem. Nesse lugar distante e margeado pelo mar, Kaushik vai enterrar a caixa de sapatos contendo as fotografias da mãe. Depois de ter quase todas as fotos arrebatas pelo vento forte, ele guarda-as na caixa e começa a fazer um buraco no chão: "Só tinha um graveto e uma pedra afiada para fazer isso, o buraco não ficou grande coisa, mas era fundo o bastante para esconder a caixa. Cobri-a com terra e pedras" (LAHIRI, 2009, p. 334). Agindo assim, ele pratica o ritual de enterro que desejava para a mãe, antes mesmo de ela morrer, como fica evidente no primeiro conto destas três narrativas: "Isso [as lápides de seis membros uma família enterrados juntos] me fez desejar que não fôssemos hindus, para minha mãe poder ser enterrada em algum lugar" (LAHIRI, 2009, p. 285). Depois desse ritual de sepultamento nesse espaço de fronteira, o protagonista masculino dá sequência à sua vida, distanciando-se definitivamente do pai e de sua nova família, indo perambular por diferentes países, numa atitude de nomadismo.

Essa característica de nômade aproxima o personagem das ideias apresentadas por Deleuze e Guattari, quando eles argumentam sobre o conceito de 


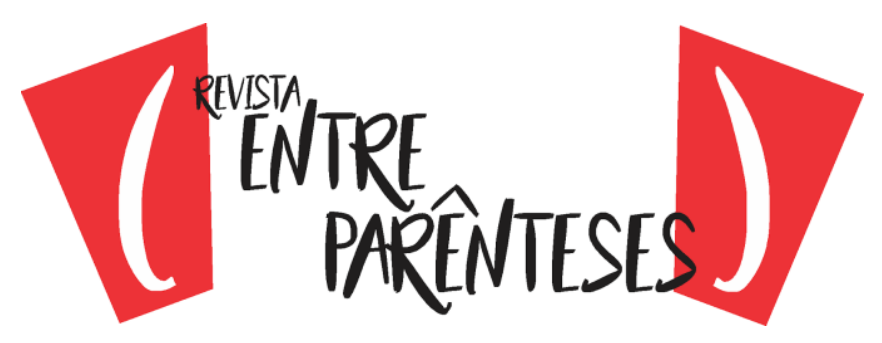

rizoma, um organismo que não se fecha, mas que se abre para diferentes direções, sempre em constante mescla identitária. Nas palavras dos estudiosos:

Um rizoma não começa nem conclui, ele se encontra sempre no meio, entre as coisas, inter-ser, intermezzo. [...]. Para onde vai você? De onde você vem? Aonde quer chegar? São questões inúteis. [...]. É que o meio não é uma média; ao contrário, é o lugar onde as coisas adquirem velocidade. Entre as coisas não designa uma correlação localizável que vai de uma para outra e reciprocamente, mas uma direção perpendicular, um movimento transversal que as carrega uma e outra, riacho sem início nem fim, que rói suas duas margens e adquire velocidade no meio (DELEUZE; GUATTARI, 1995, p. 37, grifo original).

As ações de fuga de suas raízes e de seu passado mostram a construção de um sujeito rizomático, pós-moderno e desterritorializado.

No último dos contos, "Em terra", temos uma nova voz narrativa: um narrador em terceira pessoa, seletivo múltiplo, que acompanha o reencontro de Hema e Kaushik na Itália. Na primeira parte do conto, a voz narrativa cobre a vida de Hema. Mas, logo em seguida, esta voz dá destaque à vida nômade de Kaushik até ele encontrar novamente "a única mulher a quem desejava continuar ligado" (LAHIRI, 2009, p. 370), pois ela era "a única pessoa que ele conhecera em sua vida adulta a ter qualquer compreensão sobre seu passado" (LAHIRI, 2009, p. 370).

A trajetória de nomadismo começa quando ele se forma e vai passar um tempo na América Latina. É nesse espaço novo que, em 1987, ele começa sua profissão - fotojornalismo. Devido à sua aparência física, que não o identificava como um americano, ele é visto como um estranho irreconhecível nos lugares por onde passa: "Assim como os mexicanos e guatemaltecos, os salvadorenhos nunca sabiam o que pensar de Kaushik, nem os soldados que patrulhavam as ruas [...], nem as crianças que posavam animadas para fotografias quando o viam com a câmera" (LAHIRI, 2009, p. 346). Essa visão que os outros têm dele the oferece a possibilidade de não ser identificado nem com seu país de origem, pois não possui a caracterização estereotipada do branco estadunidense, nem é visto como um indiano, pois não possui mais a marca linguística do país onde foi criado durante 


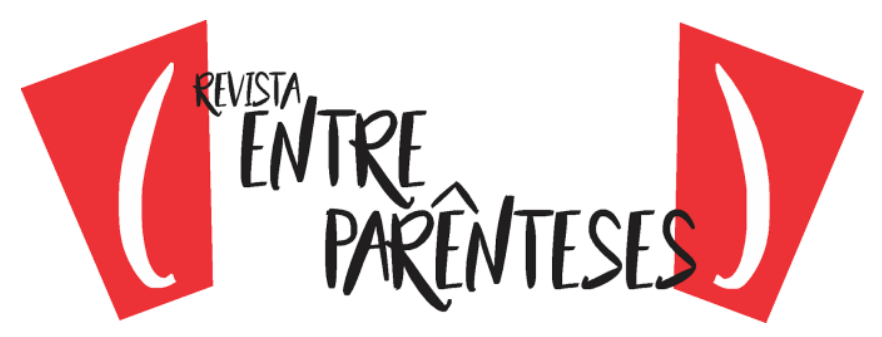

seus anos iniciais. Assim, ele é sempre um estrangeiro em qualquer país, sem nacionalidade definida.

Outro fator importante nessa vida errante de Kaushik diz respeito à sua escolha profissional. As exigências da profissão que ele escolhe "permitiam-lhe evitar os Estados Unidos de forma permanente" (LAHIRI, 2009, p. 348), o macro espaço identificado como lar e terra natal. Sua profissão também Ihe oferece uma ligação distanciada entre o que está acontecendo em frente às lentes fotográficas e o homem que comanda a máquina. Isso fica evidente em um trecho da narrativa, que mostra o modo como Kaushik lida com o assassinato de um rapaz em uma aldeia perto de Morazán, em El Salvador: "lembrava de que suas mãos tremiam, mas que, fora isso, ele se sentia alheio àquela situação, indiferente uma vez atrás da câmera, fotografando até o filme terminar" (LAHIRI, 2009, p. 348).

Seu trabalho ainda faz com que ele se distancie do passado, ligando-se sempre ao presente ou ao futuro. Como ele vive de furos jornalísticos, não lhe interessa e nem é possível registrar o passado. Suas lentes estão sempre apontando para o que está acontecendo no presente, ou para o que se projeta para um futuro próximo. A voz que conduz a narrativa faz uma ótima análise sobre essa característica profissional dele. De início, é apresentado que Kaushik despreza o passado em seu trabalho: "O seu trabalho dependia inteiramente do presente e de coisas ainda por vir" (LAHIRI, 2009, p. 359). Depois disso, o narrador cria um contraste entre a profissão dele e a de Hema, que estuda um povo morto, a civilização etrusca: "Não consistia na ressurreição repetida de textos que já haviam sido redigidos, de uma época e de um povo que não existia mais" (LAHIRI, 2009, p. 359). Diante do que nos apresenta o texto, podemos afirmar que o protagonista masculino procura se distanciar do passado, vivendo o presente ou o futuro próximo. O que suas fotografias fazem é congelar o presente, fazendo com que ele se torne uma imagem fixa. Isso é mais um motivo para ele ter facilidade de vivenciar seu nomadismo, vivendo de imagens congeladas de um eterno presente.

Com relação aos eventos históricos que Kaushik cobre como fotógrafo, é interessante notar que muitos deles lidam com questões de disputa de território, exílio, imigração: imigrantes senegaleses em Brescia; campo de refugiados em 


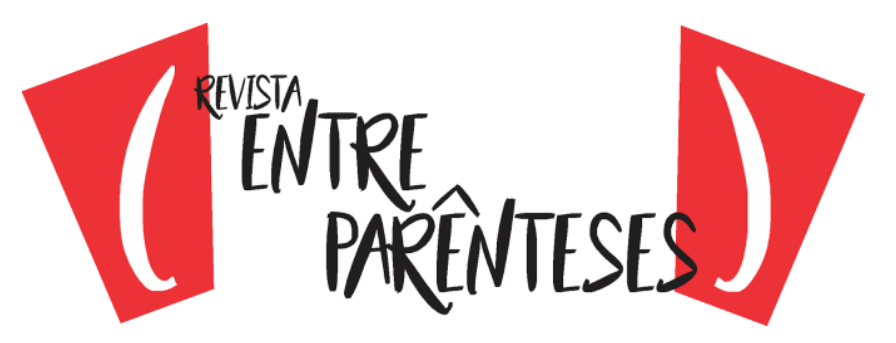

Honduras; o conflito entre a Palestina e Israel, representado pela morte do líder Yasser Arafat; soldados americanos em Israel. O registro de tais acontecimentos de conflitos migratórios ou territoriais espelha 0 interior do protagonista, que vive perdido no mundo, sempre em trânsito, procurando algo que nem ele mesmo sabe identificar. Desse modo, sua profissão é uma metáfora de si, sempre visto por um ângulo escolhido por aquele que maneja a máquina fotográfica. O que Kaushik constrói para si pode ser entendido através das palavras de Stuart Hall (2006), quando este afirma que:

Um tipo diferente de mudança estrutural está transformando as sociedades modernas no final do século XX. Isto está fragmentando as paisagens culturais de classe, gênero, sexualidade, etnia, raça e nacionalidade, que, no passado, nos tinham fornecido sólidas localizações como indivíduos sociais. Essas transformações também estão mudando as nossas identidades pessoais, abalando a ideia que temos de nós próprios como sujeitos integrados. Esta perda de um 'sentido de si' estável é chamada, algumas vezes, de deslocamento ou descentração do sujeito. Esse duplo deslocamento - descentração dos indivíduos tanto de seu lugar no mundo social e cultural quanto de si mesmos - constitui uma 'crise de identidade' para o indivíduo (HALL, 2006, p. 09).

Tomando como base o pensamento de Hall, vemos um personagem em crise. Assim, ele está prestes a chegar aos quarenta anos sem construir uma ligação sólida com ninguém. Ao pensar na idade que tem, ele lembra que sua mãe morreu com quarenta anos, depois de construir uma família. O conto nos apresenta dois relacionamentos do protagonista, que tomam o mesmo rumo, por ele não ter condições de se ligar de forma mais oficializada com suas companheiras. Com Franca, a mulher com quem dividiu um apartamento na Itália, ele inicia um relacionamento mais estável, mas, como a narrativa evidencia, ele "foi incapaz de pedi-la em casamento" (LAHIRI, 2009, p. 350), o que afastou definitivamente os dois. Isso vai acontecer novamente quando ele se aproxima de Hema. Mesmo querendo ficar com ela, Kaushik não oferece à sua antiga amiga a possibilidade de casamento, algo desejado por ela. Uma possível ligação matrimonial com Hema daria a Kaushik a chance de ele resolver os traumas do passado, uma vez que ela é a única pessoa com quem ele ficou que conhece sua história familiar, e também a 


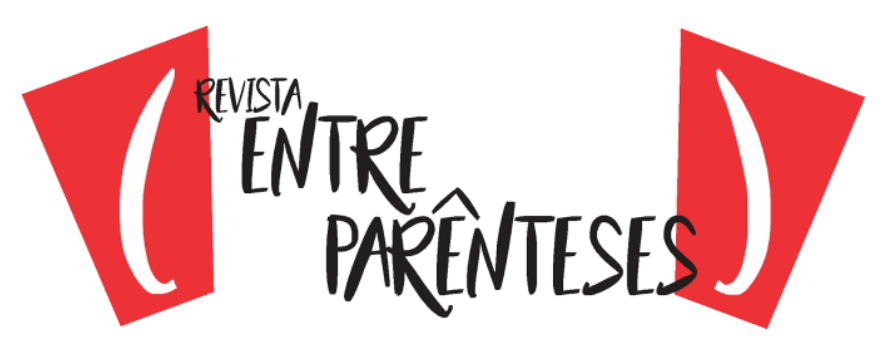

chance de construir uma família e se fixar em um local num futuro próximo. Mas ele não consegue oficializar o desejo de se unir a Hema, deixando que ela parta para casar com Navin, o homem que oferece a segurança de uma relação.

Com relação ao desejo de casamento de Hema e a negação de Kaushik para essa instituição social, uma observação deve ser feita, para entender ainda mais o nomadismo do personagem masculino. Hema deseja se casar porque seu gênero é socialmente cobrado por isso, por mais que ela use a profissão como desculpa para ficar sozinha. É por isso que ela desfaz a relação de dez anos com um homem casado, que não consegue deixar a família para construir uma nova com ela. E é por essa razão que ela aceita um casamento arranjado com Navin, mesmo amando Kaushik. Já este tem no seu gênero a liberdade de poder viajar o mundo, sem laços afetivos e sem cobranças; de vivenciar a liberdade de passear por diferentes lugares em situações de conflitos. Ao personagem masculino não é exigida uma construção matrimonial, seja pelo seu pai, seja pela sociedade das narrativas, seja por sua consciência.

A sequência das três narrativas apresenta uma variedade de espaços geográficos que podem ser agrupados em cinco denominações. O primeiro espaço é identificado como Terra natal, ou seja, os Estados Unidos, o lugar onde Kaushik nasceu, mas abandonou, juntamente com a família, quando ele ainda era uma criança. O segundo é a Terra adotiva, a Índia, onde teve que viver com os pais até a mãe ser diagnosticada com um câncer em estágio terminal. Identificado por diferentes países, temos o Local de trabalho como o terceiro espaço. O quarto diz respeito à Roma, a Terra edênica, onde ele consegue vivenciar uma relação de entrega amorosa com Hema. E, como espaço último, o conto apresenta a Terra sepulcral, representada pelo oceano Índico. Levando em conta estes cinco macro espaços, temos a trajetória de peregrinação do protagonista masculino dessas três narrativas criadas por Jhumpa Lahiri: seu nascimento, suas vivências, sua morte. Assim, vemos as três narrativas como o ciclo de nomadismo de Kaushik Choudhuri, que vivenciou diferentes espaços, mas que "nunca confiara por completo nos lugares onde havia morado, nunca recorrera a eles como refúgio" (LAHIRI, 2009, p. 353). 


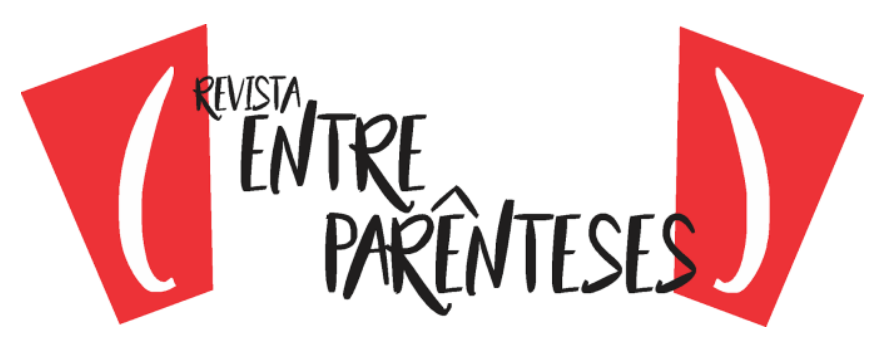

Fazendo uma leitura mais detalhada do elemento simbólico no qual Kaushik morre, a água, podemos tecer alguns comentários para entender o final do personagem. Segundo o Dicionário de símbolos, "[a]s significações simbólicas da água podem reduzir-se a três temas dominantes: fonte de vida, meio de purificação, centro de regenerescência" (CHEVALIER \& GHEERBRANT, 2009, p. 15). Aqui temos um sentido positivo, vendo-se o elemento líquido como fonte de vida, de renascimento. Usando este sentido para o estudo do conto, vemos que a morte de Kaushik ocorre em um espaço de positividade, pois ele oferece um retorno do jovem ao elemento mais adorado de sua mãe morta: a mãe teve suas cinzas jogadas no mar; pedia ao filho para "levá-la de carro até o mar" (LAHIRI, 2009, p. 295), mesmo estando doente; ela escolheu a casa de morada pela existência de uma piscina, "minha mãe usava a piscina religiosamente, nadando quarenta trajetos de ida e volta" (LAHIRI, 2009, p. 371). Assim, o conto mostra que o elemento água está associado à mãe morta. Essa associação ainda será reforçada pelo sentido que o nome da Parul carrega. O nome vem de uma palavra indiana que significa "fluxo de água"3. Como bem mostra a narrativa, Parul Mashi teve sua trajetória de vida ligada ao elemento aquático.

Ainda levando em conta o sentido do verbete "água", vemos que alguns estudiosos fazem ligações entre as águas e o feminino. Isso fica evidente no seguinte trecho ainda do Dicionário de símbolos: "[n]as tradições judaica e cristã, a água simboliza, em primeiro lugar, a origem. $\mathrm{O}$ mem (M) hebraico simboliza a água sensível: ela é mãe e matriz (útero)" (CHEVALIER \& GHEERBRANT, 2009, p. 16). Segundo Gaston Bachelard, "[a] água mistura aqui seus símbolos ambivalentes de nascimento e morte. É uma substância cheia de reminiscências e de devaneios divinatórios" (BACHELARD, 1997, p. 93). Ao explorar o sentido de morte que este elemento carrega, Gaston Bachelard, fazendo uso das palavras de Jung, afirma que:

O desejo do homem [...] é que as sombrias águas da morte se transformem nas águas da vida, que a morte e seu frio abraço sejam o regaço materno, exatamente como o mar, embora tragando o sol,

${ }^{3}$ Conferir o dicionário online: <https://www.urbandictionary.com/define.php?term=Parul>. 


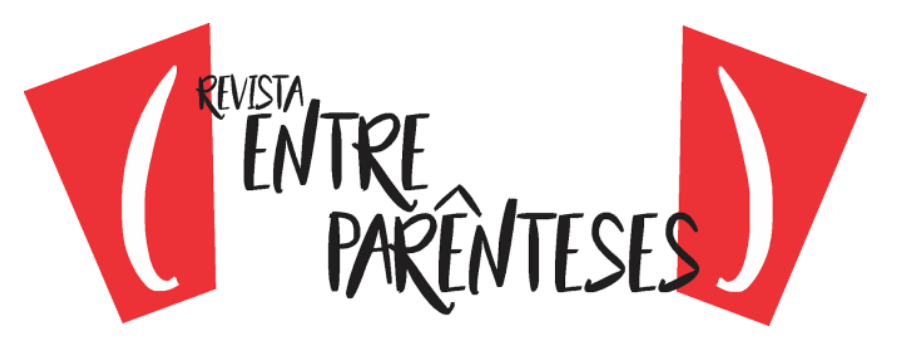

torna a pari-lo em suas profundidades... Nunca a Vida conseguiu acreditar na Morte! (BACHELARD, 1997, p. 75).

Desse modo, a morte do protagonista masculino desses três contos deve ser entendida como um retorno ao ventre materno, o primeiro espaço que ele perdeu ao nascer. Assim, através da morte nas águas, ele cria um vínculo com sua mãe, o ser de quem ele mais sente falta e de cuja perda ele não conseguiu se livrar, vivenciando um luto que o impede de se ligar completamente a outras mulheres. Ao mesmo tempo, vemos certa antítese no título da narrativa, "Em terra", em relação ao modo como Kaushik morre, nas águas. Assim, o porto seguro que ele tanto buscou, o refúgio espacial que the possibilitaria segurança surge exatamente em um elemento líquido que the traz a morte. Com esses ambientes antagônicos - terra e água - o conto constrói uma ironia para o final do personagem: ao tocar o chão do fundo do mar, quando ele acha que está seguro, ele encontra seu fim: "Kaushik se segurou na borda do barco, passou as pernas para fora e entrou n'água. O mar era morno e acolhedor como um banho de banheira. Seus pés tocaram o fundo, então ele se soltou" (LAHIRI, 2009, p. 378).

Assim, no espaço fluído, que tanto ele temia, o protagonista masculino se depara com a possibilidade de um espaço estável, mas a estabilidade, ironicamente, Ihe traz a morte. Esta morte pelas águas ainda pode ser entendida como mais uma forma de Kaushik se distanciar dos espaços que poderiam ser identificados como um lar, como um espaço para o descanso de seus restos mortais - os Estados Unidos ou a Índia - uma vez que seu corpo não é levado a um lugar onde o pai, seu parente mais próximo, possa oferecer um funeral. Tampouco seu corpo é encontrado depois que o tsunami passa. $O$ registro de sua morte é feito pelo The New York Times, que publica "um pequeno obituário" (LAHIRI, 2009, p. 379).

O título da coletânea de contos de Jhumpa Lahiri, Unaccustomed Earth (Terra descansada), apresenta-nos uma relação direta com essa tríplice sequência de histórias, que cobre a vida dos dois protagonistas, Huma e Kaushik. Esse título foi retirado do seguinte trecho do romance $A$ letra escarlate, de Nathanael Hawthorne: 


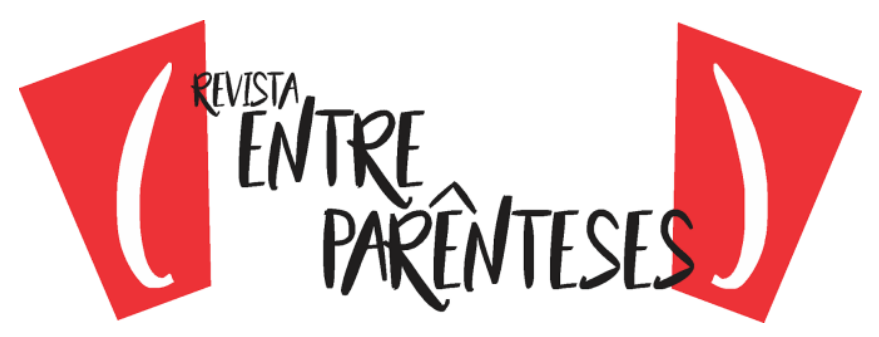

A natureza humana não irá vingar, não mais do que uma batata, se for plantada e replantada no mesmo solo exausto durante uma sequência demasiado longa de gerações. Meus filhos nasceram em outros lugares, e, até onde eu puder controlar seus destinos, irão fincar raízes em terra descansada (HAWTHORNE, apud LAHIRI, 2009 , p. 6).

A tradução da obra para o português procurou destacar a ideia apresentada na epígrafe do livro, uma vez que escolhe o vocábulo "descansada" para a palavra em inglês unaccustomed - que pode significar, também, "desconhecida", "diferente", "nova". Com o uso da palavra "descansada", a tradutora destaca o fato de a terra - lugar onde se passam as histórias, mas, também, metáfora para aculturação dos imigrantes indianos - estar pronta para o plantio, para o surgimento de nova(s) espécie(s). Assim, a escolha do nome do livro sugere que o plantio - metafórico ou não - é algo comum aos oito contos do volume. 0 título ainda alude ao fato de as oito narrativas destacarem a relação entre o solo e seus habitantes e as consequências que essa relação pode trazer.

Levando em conta essas observações sobre o título do livro, podemos afirmar que, nos três contos da segunda parte, Kaushik tem, diferente de Huma (que casa, fica grávida e inicia uma nova família), uma vida oposta ao que a epígrafe da obra apresenta. Como nunca achou um solo para seu plantio, uma vez que não se liga aos espaços em que vive e nem às pessoas com quem se relaciona, Kaushik Choudhuri retorna ao ambiente líquido de um útero metafórico para perder todas as suas raízes com a terra firme. Assim, ele é sepultado "longe dos detritos privados da vida" (LAHIRI, 2009, p. 353). 


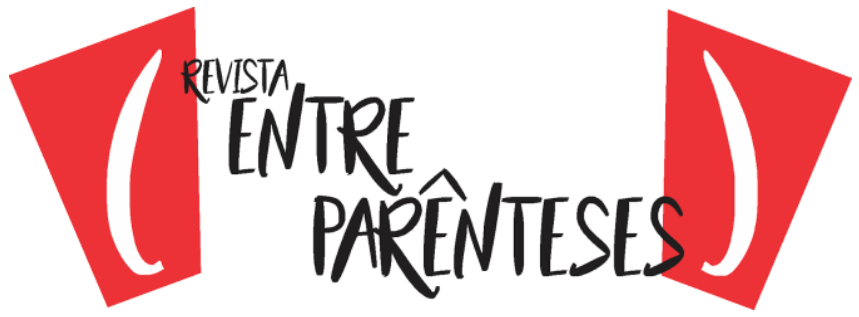

\section{Referências}

BACHELARD, Gaston. A água e os sonhos. São Paulo: Martins Fontes, 1997.

CHEVALIER, Jean; GHEERBRANT, Alain. Dicionário de símbolos: mitos, sonhos, costumes, gestos, formas, figuras, cores, número. Rio de Janeiro: José Olympio, 2009.

DELEUZE, Gilles\& GUATTARI, Felix. A thousand plateaus. Mineapolis: University of Minnesota Press, 1987.

Mil platôs - capitalismo e esquizofrenia. vol. 1. Trad. Aurélio Guerra Neto e Célia Pinto Costa. Rio de Janeiro: Editora 34, 1995.

GÁMEZ-FERNÁNDEZ, Cristina M. Delusion and defeat in the short-story sequence 'Hema and Kaushik' from Jhumpa Lahiri's Unaccustomed Earth. Routledge Taylor \& Francis Group. South Asian Diaspora. Department of English and German. Córdoba, 2016. v. 08, n. 01, p. 49-62. Disponível em: <https://www.tandfonline.com/doi/abs/10.1080/19438192.2015.1092299?journalCod e=rsad20 > .Consultado em: 18 de março de 2019.

HALL, Stuart. A identidade cultural na Pós-modernidade.Trad. Tomaz Tadeu da Silva, Guaracira Lopes Louro. 11. ed. Rio de Janeiro: DP \& A, 2006.

LAHIRI, Jhumpa. Terra Descansada: contos. Trad. Fernanda Abreu. São Paulo: Companhia das Letras, 2009.

RAHMAN, Srijoni. From Roots to Rhizomes: Hybrid, Diasporic Identities in Hema and Kaushik. York Centre for Asian Research. New Voices in Asian Research. York University. Toronto, 2017. v. 01, n. 02, p. 01-13. Disponível em:<https://yorkspace.library.yorku.ca/xmlui/bitstream/handle/10315/33674/YCAR_N VA002.pdf? sequence=1\&isAllowed=y $>$. Consultado em: 25 de março de 2019.

Recebido em: 14/04/2020

Aceito em: 16/08/2020 